\title{
Application of simple biomechanical and biochemical tests to heart valve leaflets: Implications for heart valve characterization and tissue engineering
}

Proc IMechE Part H:

$\mathrm{J}$ Engineering in Medicine

226(II) 868-876

(c) IMechE 2012

Reprints and permissions:

sagepub.co.uk/journalsPermissions.nav DOI: $10.1177 / 0954411912455004$

pih.sagepub.com

(SAGE

\author{
Hsiao-Ying S Huang', Brittany N Balhouse ${ }^{2}$ and Siyao Huang'
}

\begin{abstract}
A simple biomechanical test with real-time displacement and strain mapping is reported, which provides displacement vectors and principal strain directions during the mechanical characterization of heart valve tissues. The maps reported in the current study allow us to quickly identify the approximate strain imposed on a location in the samples. The biomechanical results show that the aortic valves exhibit stronger anisotropic mechanical behavior than that of the pulmonary valves before $18 \%$ strain equibiaxial stretching. In contrast, the pulmonary valves exhibit stronger anisotropic mechanical behavior than aortic valves beyond $28 \%$ strain equibiaxial stretching. Simple biochemical tests are also conducted. Collagens are extracted at different time points $(24,48,72$, and $120 \mathrm{~h})$ at different locations in the samples. The results show that extraction time plays an important role in determining collagen concentration, in which a minimum of $72 \mathrm{~h}$ of extraction is required to obtain saturated collagen concentration. This work provides an easy approach for quantifying biomechanical and biochemical properties of semilunar heart valve tissues, and potentially facilitates the development of tissue engineered heart valves.
\end{abstract}

\section{Keywords \\ Heart valves, real-time maps, mechanical property, collagen, microstructure}

Date received: 5 April 2012; accepted: 20 June 2012

\section{Introduction}

Heart valve leaflets are thin, collagenous tissues whose anisotropic biomechanical function depends intimately on the biochemical composition and structure. ${ }^{1}$ In disease states, the leaflets can become too stiff or too floppy. A common theme, however, in both stenotic and myxomatous disease is disturbance of the finely tuned structure-function relations governing heart valve homeostasis. ${ }^{2}$ Toward understanding the valves and how best to replace them, numerous studies have focused on characterizing their mechanical behavior, ${ }^{3-5}$ microstructural organization, 6,7 and molecular and cellular level compositions. ${ }^{8-10}$ However, while their essential anatomic peculiarities have been acknowledged for nearly a century, ${ }^{11}$ heart valve leaflets continue to challenge investigators, particularly in the context of tissue engineering. 12

Tissue engineering approaches aim to generate living native-like prosthetics from combinations of cells and biodegradable polymer scaffolds. ${ }^{13}$ The motivation for heart valve tissue engineering stems from the limitations of current replacement valves. In particular, while lifesaving, bioprosthetic valves and cryopreserved valve allografts are not permanent in young to middle-age patients, as they incur progressive calcific ${ }^{14}$ and fatiguerelated $^{15}$ degeneration during implantation. By contrast, mechanical valves, while effectively permanent, give rise to nonphysiological hemodynamics ${ }^{16}$ and are thrombogenic, requiring lifelong anticoagulation with associated bleeding risks. Perhaps paramount are the

\footnotetext{
'Department of Mechanical and Aerospace Engineering, North Carolina State University, Raleigh, NC, USA

${ }^{2}$ Department of Biomedical Engineering, North Carolina State University, Raleigh, NC, USA

\section{Corresponding author:}

Hsiao-Ying Shadow Huang, Department of Mechanical and Aerospace Engineering Department, North Carolina State University, R3I58 Engineering Building 3, Campus Box 7910, 91 I Oval Drive, Raleigh, NC 27695, USA

Email: hshuang@ncsu.edu
} 
implications for pediatric patients, for whom the lack of growth potential that is characteristic of current nonviable valve replacements mandates periodic reoperation with associated risks of morbidity and mortality. ${ }^{17}$ Introduced by Shinoka et al., ${ }^{18}$ heart valve tissue engineering has since invoked the full gamut of available technologies, ranging from noninvasively accessible stem cells ${ }^{19}$ to pulsatile flow loop bioreactors. $^{20}$ Indeed, while superficially simple, heart valve leaflets are complex tissues whose characterization, let alone recapitulation, has historically relied on mastery of specialized biochemical assays and mechanical test equipment.

Hallmarks of heart valve leaflets are their nonlinear, anisotropic mechanical response and web-like collagen network. While their prototypical soft tissue stressstrain curves - comprising toe, transition, and linear regions - can be obtained by conventional uniaxial tensile testing, ${ }^{21}$ formulation of structure-based constitutive models amenable to simulating in situ deformation has traditionally relied on biaxial testing. ${ }^{22,23}$ In particular, biaxial tensile testing data retain the influence of axial coupling, allowing for more precise predictions under generalized loading conditions. Biaxial testing devices, however, are generally custom-built and are significantly more complex than their uniaxial counterparts, including computer-coordinated control of two loading axes and optical mapping of tissue strains. ${ }^{24,25}$ For the heart valve tissue engineer, a relatively simple, commercially available biaxial tester could facilitate testing and accelerate development.

The BioTester 5000 (CellScale Biomaterials Testing, Waterloo, ON, Canada) was introduced in 2008 as a turnkey biaxial test system. ${ }^{26}$ Designed for testing planar tissues and biomaterials under physiologic conditions, the BioTester has previously been applied to materials ranging from human sclera ${ }^{27}$ to annulus fibrosa. ${ }^{28}$ In the current study, a BioTester was used to characterize the biaxial mechanical responses of porcine aortic valve (AV) and pulmonary valve (PV) leaflet tissues, providing a comparison with previously reported data, and establishing a basis for future applications. In addition, real-time motions of image features are provided, such as sample deformation and principal strain axes evolution during mechanical characterization of heart valve tissues. The maps reported in the study allow an individual to quickly identify the approximate deformation and principal directions imposed on a location in the sample. Furthermore, a biochemical analysis of collagen concentration in the heart valve tissues is also reported. Four different collagen extraction times are used, and the results indicated that the extraction time plays an important role in determining collagen concentration in native tissues. Therefore, the current study provides quantitative mechanical and biochemical data for semilunar valve tissues.

\section{Material and methods}

\section{Mechanical characterization of heart valve tissue}

Briefly, five porcine hearts from large sows (greater than 300 lbs) are obtained from the Nahunta Pork Center (Pikeville, NC) immediately after slaughtering and are returned to the laboratory within $60 \mathrm{~min}$ of sacrifice for dissection. The AV and PV are dissected from each heart, and the leaflets are removed from their respective roots. The removal is completed by cutting axially along the aorta and pulmonary artery toward the heart until the valves are reached. Each leaflet is then stretched out and held taut while being cut against the wall of the artery represented by the dashed line in Figure 1(a). A total of $13 \mathrm{AV}$ and $13 \mathrm{PV}$ leaflet samples are prepared (Figure 1(b))

For the biaxial testing, each of the six AV and PV leaflet samples $(\sim 7 \mathrm{~mm} \times 7 \mathrm{~mm})$ is marked according to the Cartesian coordinate system: the $\mathrm{x}$-axis represents the circumferential direction and the $y$-axis represents the radial direction of the heart valve tissues. Three dots are marked with a surgical marker after the samples are cut to size: one of the dots acting as the origin and the other two made to define each axis

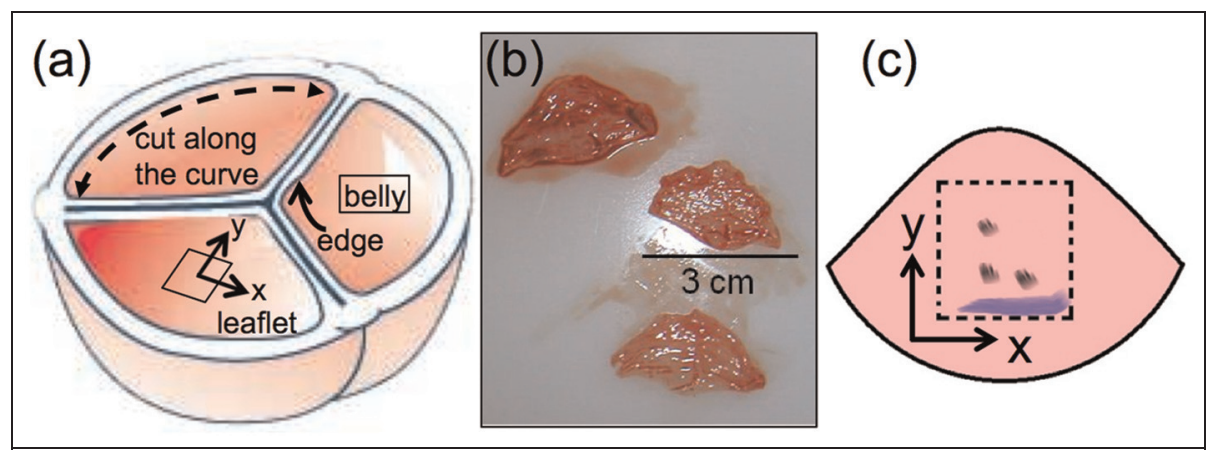

Figure I. Sample preparation. (a) Leaflets are cut against the wall of the artery represented by the dashed line, (b) three dissected leaflets, and (c) three dots are marked according to the Cartesian coordinate system: one of the dots acting as the origin and the other two made to define each axis- $x$-axis represents the circumferential direction and $y$-axis represents the radial direction of the heart valve tissues. 


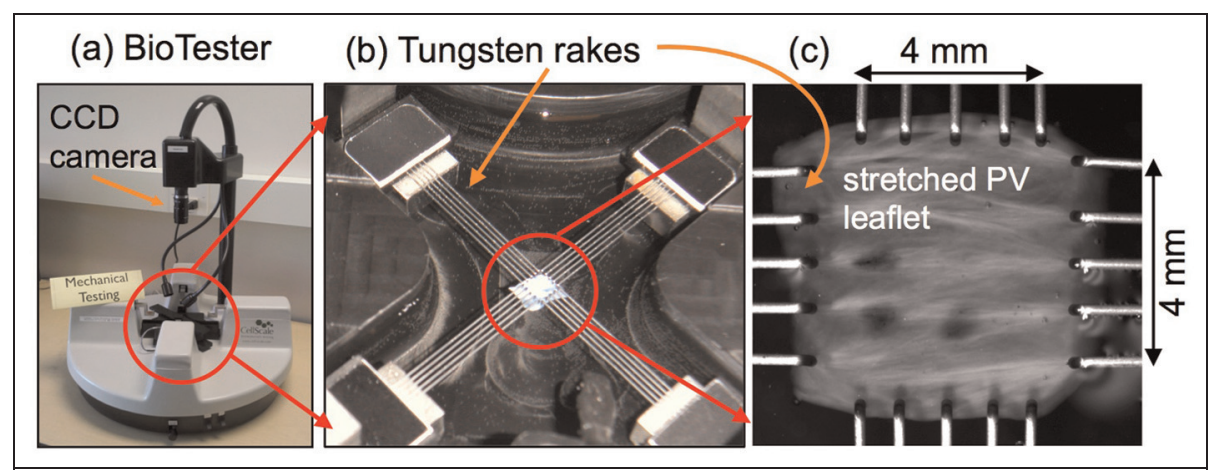

Figure 2. The BioTester is capable of applying physiologically plausible biaxial loading states to tissue samples. The tungsten rakes pierce through samples and provide evenly distributed loading. This unique feature assures the control of loading conditions and significantly reduces the variability associated with testing different sample sizes.

PV: pulmonary valve; CCD: charged-couple device.

(Figure 1(c)). The samples are stored in Hank's Balance Salt Solution (HBSS) for the relaxation.

A biaxial tissue tester (BioTester 5000), equipped with two load cells $(500 \pm 1 \mathrm{mN})$ for each axis of loading, is used for measuring the force and displacement of the semilunar heart valve tissue leaflets (Figure 2). The measured values are used to further obtain stress-strain curves and to calculate the parameters of the material's stiffness. Synchronized time lapse video for real-time monitoring and postprocess analysis is provided by the charged-couple device (CCD) camera, which acquires images with a pixel resolution of $1280 \times 960$ at an acquisition rate of $15 \mathrm{~Hz}$, with a lens focal length of $75 \mathrm{~mm}$ (Figure 2(a)). A temperature-controlled saline bath with data logging capability provides a physiological environment for testing soft tissue specimens.

Specimen mounting is considered as one of the major challenges of biaxial testing. ${ }^{26,29}$ For example, artifacts such as suturing procedures usually cause discrepancy in results due to inconsistent boundary conditions. In contrast, BioRakes provide fast and accurate sample mounting: each BioRake consists of five tungsten tines used to anchor one edge of the specimen ${ }^{26}$ (Figure 2(b)). Four rakes provide uniform attachment across the edges of the samples and evenly distribute load spanning $4 \mathrm{~mm}$ in length on each side of the sample (Figure 2(c)). This unique feature not only assures the control of boundary conditions but also significantly reduces the variability between sample sizes. In other words, if the sample size prepared is larger than $4 \mathrm{~mm}^{2}$, the active loading area remains $4 \mathrm{~mm} \times 4 \mathrm{~mm}$. After the sample is mounted, the sample is lowered into the HBSS bath, which is heated to $37^{\circ} \mathrm{C}$ to simulate an in vivo physiological environment. The heart valve leaflet samples are tested up to $35 \%$ strain on both axes with a 15 -s stretch and a 15 -s recovery, with no hold time. The image tracking and analysis software (LabJoy; CellScale), an integrated image analysis module for BioTester, is used to capture corresponding displacement and strain maps in $\mathrm{AV}$ and $\mathrm{PV}$ samples during equibiaxial testing.
Microstructures of the collagen fibers and cell nuclei are preserved for microscopic investigation via histological preparation. Histological photomicrographs of AV and PV leaflet samples are prepared as follows: The leaflets under $0 \%$ strain were fixed in $10 \%(\mathrm{v} / \mathrm{v})$ buffered formalin, paraffin embedded, sectioned, and stained with Masson's trichrome. The collagen fibers stained by Masson's trichrome appear blue, whereas the cell nuclei appear dark brown to black. Each histological slide cutting in the $\mathrm{x}-\mathrm{y}$ plane (en face section) is quantified from the fibrosa layer. The histological slides were digitized as photomicrographs via a Leica DM LB optical microscope (Leica Microsystems, Wetzlar, Germany) at $400 \times$ magnification using techniques adapted from published articles. ${ }^{9}$

\section{Biochemical analysis of heart valve tissue}

Collagen concentrations (collagen types I, III, and V) of the semilunar valve leaflets are determined via an assay kit (Sircol; Accurate Chemical \& Scientific Corp., Westbury, NY) by using techniques adapted from published articles. ${ }^{30-33}$ In brief, 84 samples $(\sim 25 \mathrm{~mm} \times 1$ $\mathrm{mm} \times 1 \mathrm{~mm}$ ) obtained from seven valves are prepared. For each valve, three samples are cut from the belly region and three samples are cut from the free edges of the leaflets (Figure 1(a)). The samples are weighed using an analytical balance (VWR, West Chester, PA).

Collagen extraction. To allow the collagen to be extracted from the tissue, $100 \mathrm{~mL}$ of collagen extraction solution is prepared, composed of $97.14 \mathrm{~mL}$ of distilled water, $2.86 \mathrm{~mL}$ of $17.5 \mathrm{~N}$ acetic acid (Sigma-Aldrich, St. Louis, MO), and $100 \mathrm{mg}$ of pepsin (Sigma-Aldrich). A temporal parametric study is performed to obtain maximum collagen concentration from heart valve tissues. Collagen extraction solution of $1 \mathrm{~mL}$ is added to each tube, and samples are placed on a vortex mixer (VWR, West Chester, PA) for 24, 48, 72, and $120 \mathrm{~h}$, respectively. The collagen concentration is quantified based 


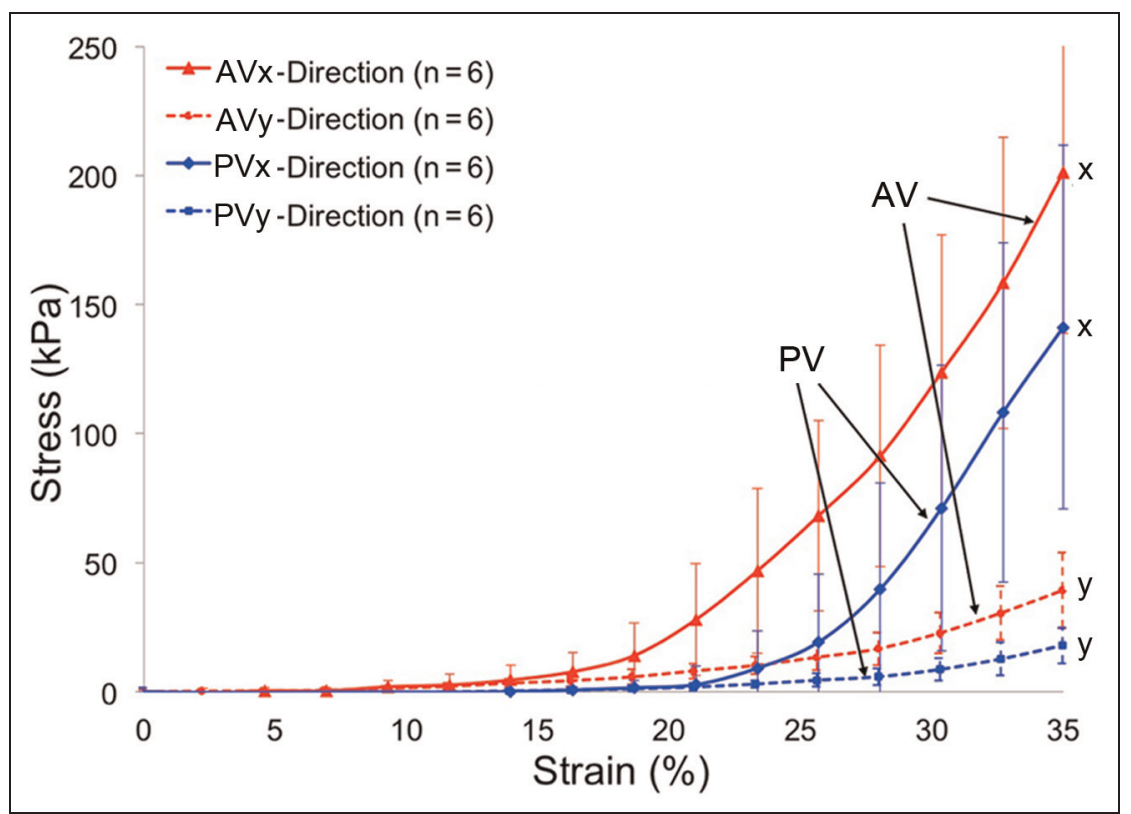

Figure 3. Stress-strain curves for $A V$ and $P V$ tissue samples at different orientations. A nonlinear anisotropic mechanical property is observed in both $\mathrm{AV}$ and PV tissue samples. Three zones are observed: zone I (0\%-18\% strain), zone 2 ( $18 \%-28 \%$ strain), and zone 3 ( $28 \%-35 \%$ strain). $\mathrm{AV}$ : aortic valve; $\mathrm{PV}$ : pulmonary valve.

on the precalculated collagen standard curve described as follows.

Collagen standard curve. Four standards are prepared using $0.5 \mathrm{mg} / \mathrm{mL}$ collagen standard (Sircol; Accurate Chemical and Scientific Corp., Westbury, NY) with four different volumes: $100 \mu \mathrm{L}, 50 \mu \mathrm{L}, 25 \mu \mathrm{L}$, and blank: $0 \mu \mathrm{L}$. The mass of collagen is calculated based on the concentration and volumes, and results in 50, 25, 12.5 , and $0 \mu \mathrm{g}$, respectively. Four extraction solutions, $0,50,75$, and $100 \mu \mathrm{L}$, respectively, are then added to four microcentrifuge tubes to make up a total volume of $100 \mu \mathrm{L}$ for each tube.

Collagen content quantification. The collagen content is dyed with $1 \mathrm{~mL}$ of reagent (Sirius red dye, picric acid, and surfactants), dissolved in $1 \mathrm{~mL}$ of alkali reagent, and quantified via a spectrophotometer (Thermo Fisher Scientific, Waltham, MA). A collagen standard curve $\left(y=0.0246 x, \quad R^{2}=0.9963\right)$ is established via four absorbance values from the standards, where $\mathrm{y}$ is the absorbance value at $550 \mathrm{~nm}$, $\mathrm{x}$ is the mass of collagen, and $\mathrm{R}$ is the correlation coefficient between $\mathrm{x}$ and $\mathrm{y}$. The collagen masses of 84 samples are calculated by comparing absorbance values to that of the collagen standards. The collagen concentration of each sample is then calculated by normalizing to the wet weight of the individual collagen sample.

\section{Statistical analysis}

Data are presented as the means \pm standard deviations. The number of experimental samples is represented as n. Student's $t$-tests are used to test differences in population means. Differences with $\mathrm{p}<0.05$ are considered significant.

\section{Results and discussion}

\section{Mechanical properties of heart valves}

After averaging over measured stress versus strain for AV and PV leaflets samples under equibiaxial testing, the results are shown in Figure 3. The plot shows the correlation between the strain and the resulting stress in the circumferential (x-axis) and radial (y-axis) directions for both AV and PV tissue samples. The stress-strain curves are calculated based on the displacements of 81 tracked points, as defined inside the red boxes (Figure 4). These red boxes are user defined and located $1.5 \mathrm{~mm}$ inward from the boundary. The aim is to reduce any potentially confounding effects on the stress-strain data associated with potential stress concentrations and/or inhomogeneous strains manifesting in the peripheral region of the tissue specimen gripped by the rakes. In Figure 3, three zones are observed: zone 1 is between $0 \%$ and $18 \%$ strain stretching, zone 2 is between $18 \%$ and $28 \%$ strain stretching, and zone 3 is between $28 \%$ and $35 \%$ strain stretching. Under equibiaxial stretching, it is observed that high standard deviations exist when samples are tested above $18 \%$ strain. It could be due to the sensitivity of load cells and where force data were collected and averaged inside the red boxes. Piecewise parameters of material stiffness of valvular tissues in three zones are listed in Tables 1 and 2, and values are expressed as means \pm standard deviations for AV and PV samples. Stress-strain curves in zone 1 provide moduli of elasticity of AV and PV tissues and stress-strain curves in zones 2 and 3 provide 


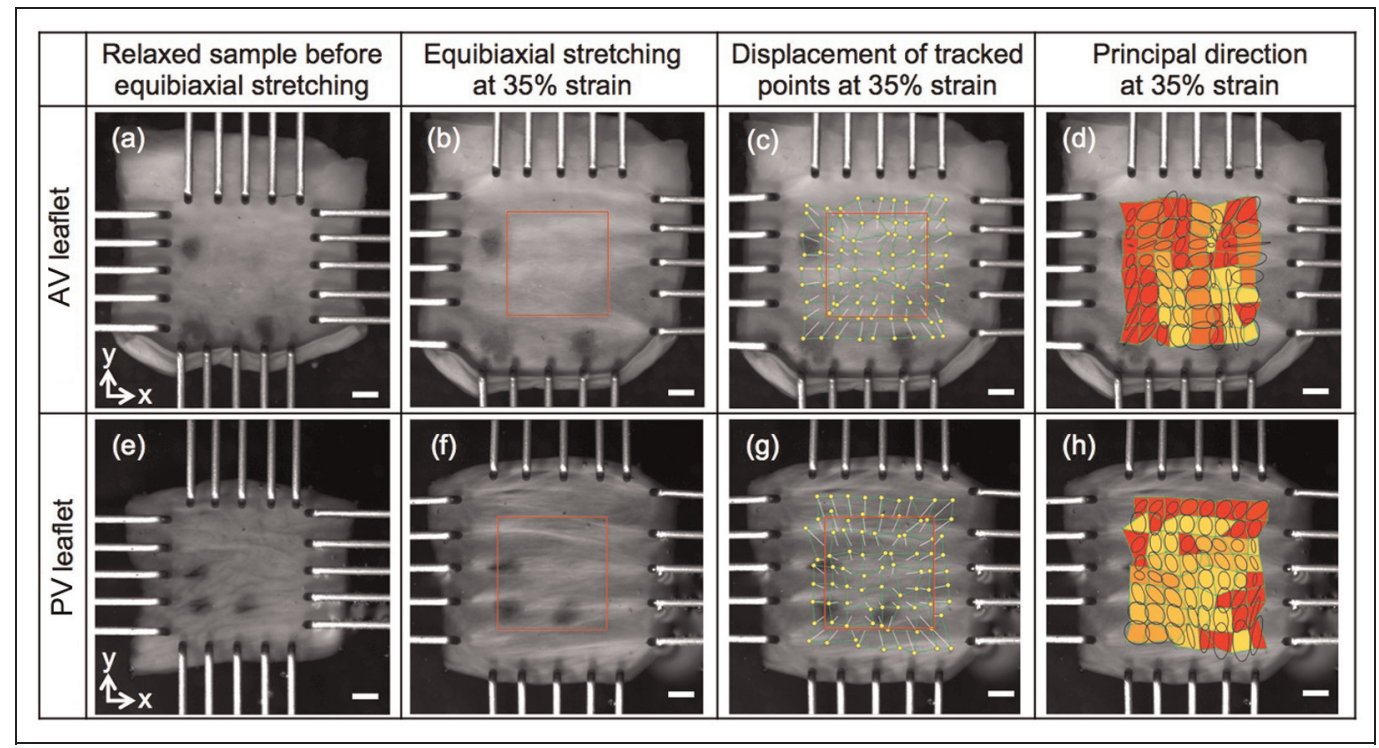

Figure 4. Corresponding macroscopic appearance of $\mathrm{AV}$ and $\mathrm{PV}$ samples under equibiaxial testing. Maps of displacement and principal strain are shown at 35\% equibiaxial stretching. Collagen bundles are observed in PV samples. (Color online) Color key: Dark shade $($ red $)=25 \%$ strain, and light shade $($ yellow $)=15 \%$ strain. Scale bar: $1 \mathrm{~mm}$. $\mathrm{AV}$ : aortic valve; PV: pulmonary valve.

Table I. Modulus of elasticity of valvular tissues in zone I.

\begin{tabular}{|c|c|}
\hline $\mathrm{E}(\mathrm{kPa})$ & $0 \%-18 \%$ of strain (zone I) \\
\hline$A V x$-direction $\left(E_{A y}^{(I)}\right)$ & $89.1 \pm 4.63$ \\
\hline$A V$ y-direction $\left(E_{A v y}^{(I)}\right)$ & $33.94 \pm 1.37$ \\
\hline$P V x$-direction $\left(E^{(1)}\right)$ & $\mid 1.31 \pm 0.79$ \\
\hline PV y-direction $\left(E_{\mathrm{pyy}}^{(1)}\right)$ & $11.67 \pm 0.61$ \\
\hline
\end{tabular}

AV: aortic valve; PV: pulmonary valve.

Table 2. Tangent modulus of elasticity of valvular tissues in zones 2 and 3.

\begin{tabular}{|c|c|c|}
\hline $\mathrm{E}^{\tan }(\mathrm{kPa})$ & $\begin{array}{l}18 \%-28 \% \text { of } \\
\text { strain (zone } 2 \text { ) }\end{array}$ & $\begin{array}{l}28 \%-35 \% \text { of } \\
\text { strain (zone } 3 \text { ) }\end{array}$ \\
\hline $\mathrm{AV} \times \mathrm{x}$-direction $\left(\mathrm{E}_{\mathrm{AV} \mathrm{x}}^{\mathrm{tan}}\right)$ & $825.11 \pm 29.19$ & $1577.17 \pm 53.69$ \\
\hline$A V y$-direction $\left(E_{A V y}^{A t a n}\right)$ & $116.43 \pm 4.15$ & $324.93 \pm 9.84$ \\
\hline $\mathrm{PV} x$-direction $\left(\mathrm{E}_{\mathrm{PV} \mathrm{x}}^{\mathrm{tan}}\right)$ & $408.23 \pm 18.34$ & $1457.19 \pm 58.1$ \\
\hline$P V y$-direction $\left(\mathrm{E}_{\mathrm{PVy}}^{\mathrm{Pan}}\right)$ & $50.16 \pm 2.01$ & $172.44 \pm 5.24$ \\
\hline
\end{tabular}

$\mathrm{AV}$ : aortic valve; PV: pulmonary valve.

tangent moduli of elasticity. The differences between the direction-dependent stress versus strain curves in AV and PV tissue samples are mainly due to collagen fiber arrangements. ${ }^{7,34-36}$ Most of the collagen fibers in AV and PV align circumferentially, and therefore, stiffer mechanical properties in the $\mathrm{x}$-direction are observed, whereas collagen fibers in the PV sample are more randomly distributed than the ones in the AV samples (Figure 5).

\section{Mechanical behaviors and their relation to collagen fiber microstructures}

In zone $1(0 \%-18 \%$ strain $)$, it is observed that the stiffness in the $\mathrm{x}$-direction is more than twice that in the $\mathrm{y}$ direction for $\mathrm{AV}$ samples $\left(\mathrm{E}_{\mathrm{AVx}}^{(1)} / \mathrm{E}_{\mathrm{AVy}}^{(1)}=2.6\right)$, suggesting that AV has a slightly anisotropic material property in zone 1 (Table 1 and Figure 3). In contrast, the stiffness is comparable in the $\mathrm{x}$ - and $\mathrm{y}$-directions for $\mathrm{PV}$ samples $\left(\mathrm{E}_{\mathrm{PV}}^{(1)} / \mathrm{E}_{\mathrm{PVy}}^{(1)}=0.969\right)$, suggesting that PV exhibits an isotropic material property in zone 1 . This could be due to randomly distributed collagen fibers in PV samples not being fully aligned along the circumferential direction before reaching $18 \%$ biaxial stretching, as shown in Figure 5. The result also shows that AV samples are more than 7 times stiffer than PV samples in the $\mathrm{x}$ direction $\left(\mathrm{E}_{\mathrm{AVx}}^{(1)} / \mathrm{E}_{\mathrm{PVx}}^{(1)}=7.8\right)$, but in the y-direction, $\mathrm{AV}$

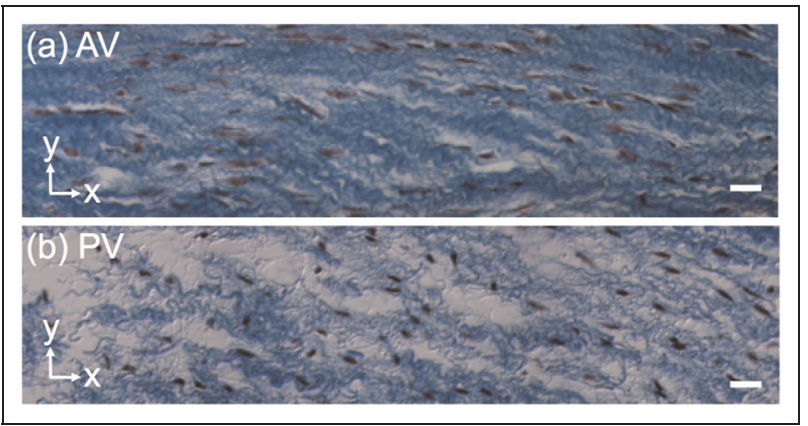

Figure 5. En face histological photomicrographs of $A V$ and $P V$ samples under $0 \%$ strain. Tissues are stained by Masson's trichrome, in which collagen fibers are in blue and cell nuclei are in black. (a) Most of the collagen fibers in AV samples are along the x-direction. (b) Randomly distributed collagen fibers are observed in PV samples. Scale bar: $10 \mu \mathrm{m}, \times 400$. $\mathrm{AV}$ : aortic valve; $\mathrm{PV}$ : pulmonary valve. 
samples are only 3 times stiffer than PV samples $\left(\mathrm{E}_{\mathrm{AVy}}^{(1)} /\right.$ $\mathrm{E}_{\mathrm{PVy}}^{(1)}=3$ ) (Table 1 and Figure 3). It is suggested that collagen fibers in AV samples align with the circumferential direction sooner than those in the PV samples before reaching $18 \%$ biaxial stretching.

In zone $2(18 \%-28 \%$ strain), it is observed that the stiffness in the $\mathrm{x}$-direction is more than 7 times higher than that in the $\mathrm{y}$-direction for both the $\mathrm{AV}$ and $\mathrm{PV}$ samples $\left(\mathrm{E}_{\mathrm{AVx}}^{\tan (2)} / \mathrm{E}_{\mathrm{AVy}}^{\tan (2)}=7.0\right.$ and $\mathrm{E}_{\mathrm{PV}_{\mathrm{x}}}^{\tan (2)} / \mathrm{E}_{\mathrm{PVy}}^{\tan (2)}=8.13$, respectively), as shown in Table 2 and Figure 3. This finding is comparable to the one reported by Lewinsohn et al. ${ }^{3}$ via uniaxial tensile testing and correlates well with the range in previous mechanical characterization studies via force-control biaxial testing. $^{23,25,36}$ The similar $\mathrm{x}$ to $\mathrm{y}$ ratio for the mechanical property observed in zone 2 suggests that the distribution of collagen fibers along the circumferential direction versus that along the radial direction is comparable in both AV and PV samples: the degree of anisotropy of fiber distribution is similar. AV samples are twice as stiff as PV samples in both the $\mathrm{x}$ - and y-directions $\left(\mathrm{E}_{\mathrm{AVx}}^{\tan (2)} / \mathrm{E}_{\mathrm{PVx}}^{\tan (2)}=2.0\right.$ and $\mathrm{E}_{\mathrm{AVy}}^{\tan (2)} / \mathrm{E}_{\mathrm{PVy}}^{\tan (2)}=$ 2.3), and it is suggested that collagen fibers exhibit similar arrangements in the AV and PV samples between $18 \%$ and $28 \%$ strain (Table 2 and Figure 3 ). However, it is still not clear which intrinsic biological characteristic gives rise to the interesting microstructure features of collagen fibers that reflect back to the measured mechanical property in zone 2 .

In zone $3(28 \%-35 \%$ strain $)$, it is observed that the stiffness in the $\mathrm{x}$-direction is more than 4 times higher than that in the $\mathrm{y}$-direction for $\mathrm{AV}$ samples $\left(\mathrm{E}_{\mathrm{AVx}}^{\tan (3)} /\right.$ $\left.\mathrm{E}_{\mathrm{AVy}}^{\tan (3)}=4.85\right)$, where the $\mathrm{x}$ to $\mathrm{y}$ ratio is lower than that in zone $2\left(\mathrm{E}_{\mathrm{AVx}}^{\tan (2)} / \mathrm{E}_{\mathrm{AVy}}^{\tan (2)}=7\right)$ (Table 2 and Figure 3). The decreased $\mathrm{x}$ to $\mathrm{y}$ ratio of this mechanical property in AV samples suggests that collagen fibers experience most realignment and straightening in zone 2, and therefore exhibit a linear elastic mode in zone 3 . Different results are observed for PV samples and indicate that the stiffness in the $\mathrm{x}$-direction is more than 8 times higher than that in the y-direction in zone 3 $\left(\mathrm{E}_{\mathrm{PVx}}^{\tan (3)} / \mathrm{E}_{\mathrm{PVy}}^{\tan (3)}=8.5\right)$, and it has a similar $\mathrm{x}$ to $\mathrm{y}$ ratio to that observed in zone $2\left(\mathrm{E}_{\mathrm{PVx}}^{\tan (2)} / \mathrm{E}_{\mathrm{PVy}}^{\tan (2)}=8.13\right)$ (Table 2 and Figure 3). This suggests that collagen fibers exhibit higher anisotropy in PV than that in $\mathrm{AV}$ in zone 3. Therefore, a higher degree of straightening is required for collagen fibers to be fully aligned between $28 \%$ and $35 \%$ strain stretching for PV samples, suggesting that collagen fibers are more randomly distributed in the PV leaflets than in the AV leaflets. It is observed that the stiffness is similar in the $\mathrm{x}$-direction for both $\mathrm{AV}$ and PV samples $\left(\mathrm{E}_{\mathrm{AVx}}^{\tan (3)} / \mathrm{E}_{\mathrm{PVx}}^{\tan (3)}=1.08\right)$, but in the $\mathrm{y}$-direction, the stiffness of AVs is almost twice that of PVs $\left(\mathrm{E}_{\mathrm{AVy}}^{\tan (3)} / \mathrm{E}_{\mathrm{PVy}}^{\tan (3)}=1.88\right)$.

Comparing to the result in zone 1, an almost 10 -fold increase in the stiffness in the $\mathrm{x}$-direction for $\mathrm{AV}$ samples is observed $\left(\mathrm{E}_{\mathrm{AV} \mathrm{x}}^{\tan (2)} / \mathrm{E}_{\mathrm{AV} \mathrm{x}}^{\tan (1)}=9.3\right)$, whereas a substantial increase ( $\sim 36$ times) in the stiffness in the $\mathrm{x}$-direction for $\mathrm{PV}$ samples is measured $\left(\mathrm{E}_{\mathrm{PV}_{\mathrm{x}}}^{\tan (2)} /\right.$ $\left.\mathrm{E}_{\mathrm{PVx}}^{\tan (1)}=36\right)$. In contrast, only three- and fourfold increase in the stiffness in the y-direction for both $\mathrm{AV}$ and PV samples is observed $\left(\mathrm{E}_{\mathrm{AVy}}^{\tan (2)} / \mathrm{E}_{\mathrm{AVy}}^{(1)}=3.43\right.$ and $\mathrm{E}_{\mathrm{PVy}}^{\tan (2)} / \mathrm{E}_{\mathrm{PVy}}^{(1)}=4$, respectively). These results confirm that this highly anisotropic material property in heart valve tissues is dominated by the orientation of circumferentially aligned collagen fibers. ${ }^{7,34,36}$ Moreover, collagen fibers in PV samples exhibit stronger realignment beyond $18 \%$ strain, and the materials exhibit anisotropically, rather than isotropically, as ones observed in zone 1.

Comparing the ratios in zone $2\left(\mathrm{E}_{\mathrm{AVx}}^{\tan (2)} / \mathrm{E}_{\mathrm{PV}_{\mathrm{x}}}^{\tan (2)}=2.0\right.$ and $\left.\mathrm{E}_{\mathrm{AVy}}^{\tan (2)} / \mathrm{E}_{\mathrm{PVy}}^{\tan (2)}=2.0\right)$, the ratios between samples in zone 3 are slightly lower $\left(\mathrm{E}_{\mathrm{AVx}}^{\tan (3)} / \mathrm{E}_{\mathrm{PV}_{\mathrm{x}}}^{\tan (3)}=1.08\right.$ and $\left.\mathrm{E}_{\mathrm{AVy}}^{\tan (3)} / \mathrm{E}_{\mathrm{PVy}}^{\tan (3)}=1.88\right)$. Moreover, the stiffness of $\mathrm{AV}$ and PV samples in both the $\mathrm{x}$ - and $\mathrm{y}$-directions are consistently two- and threefold higher than the ones in zone $2\left(\mathrm{E}_{\mathrm{AVx}}^{\tan (3)} / \mathrm{E}_{\mathrm{AVx}}^{\tan (2)}=2.0, \mathrm{E}_{\mathrm{AVy}}^{\tan (3)} / \mathrm{E}_{\mathrm{AVy}}^{\tan (2)}=2.8, \quad \mathrm{E}_{\mathrm{PVx}}^{\tan (3)} /\right.$ $\mathrm{E}_{\mathrm{PVx}}^{\tan (2)}=3.6$, and $\left.\mathrm{E}_{\mathrm{PVy}}^{\tan (3)} / \mathrm{E}_{\mathrm{PVy}_{\mathrm{y}}}^{\tan (2)}=3.4\right)$, suggesting that collagen fiber alignment in both $\mathrm{AV}$ and PV tissues is saturated when samples are stretched above $28 \%$ strain (Table 1 and Figure 3).

It has been observed that the peak level of physiological strain experienced by the PV in vivo is approximately $35 \%$; in the current in vitro study, it was recognized in pilot experiments that PV samples began to tear when stretched above $35 \%$ strain, consistent with observations reported in other studies. ${ }^{37,38}$ In this study, it is intended to conduct a parametric study comparing AV and PV mechanical properties. Therefore, tissue samples are biaxially stretched only up to $35 \%$ strain. For details on how AVs mechanically behave above $35 \%$ strain, the reader should refer to other studies. $^{3}$

\section{Real-time strain maps in heart valve tissues}

Corresponding macroscopic appearances of AV and PV samples under equibiaxial testing are captured via an integrated image analysis module of BioTester. This imaging tracking and analysis software was used to review and analyze images collected during our biaxial testing (Figure 2(c)). Motion of image features, such as specimen texture and fiducial markers, was recorded and used to study localized AV and PV sample deformations, strain magnitudes, and principal axes (Figure 4). Relaxed AV and PV samples before the equibiaxial testing are shown in Figure 4(a) and (e). For sample stretching, four rakes provide evenly distributed loading spanning $4 \mathrm{~mm}$ in length on each side of the sample. Figure 4(b) and (f) show that AV and PV samples are stretched up to $35 \%$ equibiaxially. The PV leaflets are generally thinner than $\mathrm{AV}$ leaflets $(0.38$ and $0.56 \mathrm{~mm}$, 


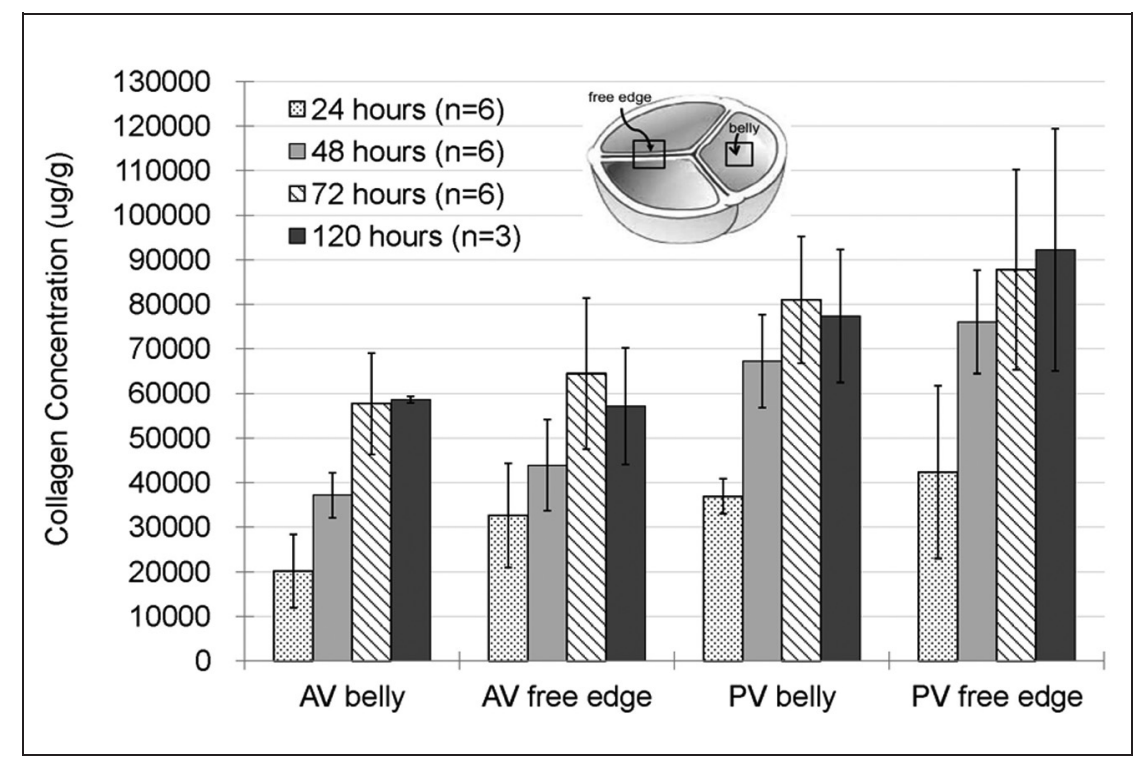

Figure 6. Collagen concentration at four different time points $(24,48,72$, and $120 \mathrm{~h})$. The result indicates that the extraction time plays an important role in determining collagen concentration in native heart valve tissues. It is shown that collagen concentration depends strongly on the location and valve type.

$\mathrm{AV}$ : aortic valve; $\mathrm{PV}$ : pulmonary valve.

respectively). Therefore, under equibiaxial testing, fiber bundles parallel to the circumferential direction in the PV samples are shown more clearly than the ones in the AV samples. Displacements of tracked points under equibiaxial 35\% strain are shown in Figure 4(c) and $(\mathrm{g})$. The red boxes define the reference containing 81 points at $0 \%$ strain. The dots (color online: in yellow) indicate the locations of these 81 points when samples are biaxially stretched at $35 \%$. The tails (color online: in green) indicate the relative displacements of tracked points from ones at previous $(\sim 32 \%)$ strain. The map of principal axes for deformed AV and PV samples at 35\% equibiaxial stretch is shown in Figure 4(d) and (h). The principal axes are shown as black circles, and they are averaged across 16 points via the integrated image analysis module. The darker shade (color online: in red) in the map indicates a higher strain value $(25 \%)$, and the lighter shade (color online: in yellow) indicates a lower strain value $(15 \%)$.

\section{Collagen concentration}

The collagen concentration is calculated by normalizing the wet weights of individual collagen samples at different time points $(24,48,72$, and $120 \mathrm{~h})$, in which the averaged weight of AV leaflet samples in the belly region and the free edge are 0.0336 and $0.0186 \mathrm{~g}$, respectively. The averaged weights of the PV leaflet samples in the belly region and the free edge are 0.0241 and $0.0161 \mathrm{~g}$, respectively. It is observed that the extraction time plays an important role in determining collagen concentration in native tissues, for which a minimum of $72 \mathrm{~h}$ of extraction is required to obtain a saturated collagen concentration (Figure 6); the collagen concentration in native heart tissues after $72 \mathrm{~h}$ is more than twice as much as those after $24-\mathrm{h}$ extraction.
It is suggested that tissue engineered heart valve constructs should be designed to have native collagen concentration values comparable to native ones extracted for $72 \mathrm{~h}$, as reported in the current study. Furthermore, the result shows that the collagen concentration is location dependent. It is observed that samples from free edges have higher collagen concentrations than those from belly regions, in both AV and PV samples. It was recently demonstrated that branching fiber bundles could be observed via polarized light microscopy along free edges of heart valve leaflets. ${ }^{6}$ Our result suggests that our higher measured collagen concentration at free edges can be attributed to these fiber bundles, which begin at the annulus and branch as they traverse toward the belly region of the leaflets. Finally, the result shows that native PV tissue samples have higher collagen concentrations than those in the native AV tissue samples (Figure 6), suggesting that collagen concentration is valve type dependent. The lower concentration found in AV samples is attributed to the wet weight in the current study. Since AV samples have higher average wet weight, lower collagen concentration is obtained. Although AVs have higher mechanical strength than that of PVs, previous studies have shown that elasticity moduli are correlated with collagen cross-link concentration, rather than collagen concentration in the leaflets. ${ }^{38}$ Since collagen concentration extraction time is the focus of the current study, readers should refer to Balguid et al. ${ }^{38}$ for more details about cross-links in native heart valve tissues.

\section{Conclusion}

In the current study, a synergy approach is reported and aimed at understanding the interplay of heart valve 
tissue mechanical property and microstructures, with special emphasis on collagen content over different extraction time. The current study provides a simple method to investigate the mechanical properties of heart valve tissues with corresponding real-time displacement vectors and principal strain maps. The maps reported in this study allow an individual to quickly identify the approximate strain imposed on a location in the sample, as well as to detect any potential grip effects that generally cause discrepant results due to inconsistent boundary conditions. Moreover, en face microstructures of collagen fibers are panoramically examined and are correlated to the mechanical behavior of heart valve tissue leaflets. From the measured stress-strain curves, three zones are observed. In zone 1 ( $0 \%-18 \%$ strain), AV has a slightly anisotropic material property; however, $\mathrm{PV}$ exhibits an isotropic material property. In zone $2(18 \%-28 \%$ strain $)$, the distribution of collagen fibers along the circumferential direction versus that along the radial direction is comparable in both AV and PV samples, suggesting that collagen fibers exhibit similar arrangements in the AV and PV samples. In zone 3 (28\%-35\% strain), collagen fibers exhibit higher anisotropy in PV than that in AV. Moreover, the stiffnesses of AV and PV samples in both the circumferential and radial directions are consistently two- and threefold higher than ones in zone 2, suggesting that collagen fiber alignment in both AV and PV tissues is saturated when samples are stretched above $28 \%$ strain. In addition, the collagen concentration in the native semilunar heart valves are also reported, and it is observed that the extraction time plays an important role in determining collagen concentration in native tissues. The current study provides quantitative mechanical and biochemical data for semilunar heart valve tissues. The result of the study will culminate in synergistic activities between experimental and clinical efforts aimed at breakthroughs in the clinical treatment of heart valve diseases and the development of tissue engineered heart valves.

\section{Funding}

This research is partly supported by the Faculty Research and Professional Development at North Carolina State University.

\section{References}

1. Sacks MS, Merryman WD and Schmidt DE. On the biomechanics of heart valve function. J Biomech 2009; 42(12): 1804-1824.

2. Schoen FJ. Mechanisms of function and disease of natural and replacement heart valves. Annu Rev Pathol 2012; 7: 161-183.

3. Lewinsohn AD, Anssari-Benham A, Lee DA, et al. Anisotropic strain transfer through the aortic valve and its relevance to the cellular mechanical environment. Proc.
IMechE, Part H: J Engineering in Medicine 2011; 225(8): 821-830.

4. Koch TM, Reddy BD, Zilla P, et al. Aortic valve leaflet mechanical properties facilitate diastolic valve function. Comput Methods Biomech Biomed Engin 2010; 13(2): 225-234.

5. Stella JA and Sacks MS. On the biaxial mechanical properties of the layers of the aortic valve leaflet. $J$ Biomech Eng 2007; 129(5): 757-766.

6. Doehring TC, Kahelin M and Vesely I. Mesostructures of the aortic valve. $J$ Heart Valve Dis 2005; 14(5): 679-686.

7. Joyce EM, Liao J, Schoen FJ, et al. Functional collagen fiber architecture of the pulmonary heart valve cusp. Ann Thorac Surg 2009; 87(4): 1240-1249.

8. Latif N, Sarathchandra R, Taylor RM, et al. Molecules mediating cell-ECM and cell-cell communication in human heart valves. Cell Biochem Biophys 2005; 43(2): 275-287.

9. Huang H-Y, Liao J and Sacks MS. In-situ deformation of the aortic valve interstitial cell nucleus under diastolic loading. J Biomech Eng 2007; 129: 880-889.

10. Filip DA, Radu A and Simionescu M. Interstitial-cells of the heart-valves possess characteristics similar to smoothmuscle cells. Circ Res 1986; 59(3): 310-320.

11. Gross L and Kugel MA. Topographical anatomy and histology of the valves in the human heart. Am J Pathol 1931; 7: 445-474.

12. Sacks MS, Schoen FJ and Mayer JE Jr. Bioengineering challenges for heart valve tissue engineering. Аnпu Rev Biomed Eng 2009; 11: 289-313.

13. Langer $\mathrm{R}$ and Vacanti JP. Tissue engineering. Science 1993; 260(5110): 920-926.

14. Schoen FJ and Levy RJ. Calcification of tissue heart valve substitutes: progress toward understanding and prevention. Ann Thorac Surg 2005; 79(3): 1072-1080.

15. Sacks MS. The biomechanical effects of fatigue on the porcine bioprosthetic heart valve. J Long Term Eff Med Implants 2001; 11(3-4): 231-247.

16. Dasi LP, Simon HA, Sucosky P, et al. Fluid mechanics of artificial heart valves. Clin Exp Pharmacol Physiol 2009; 36(2): 225-237.

17. Perron J, Moran AM, Gauvreau K, et al. Valved homograft conduit repair of the right heart in early infancy. Ann Thorac Surg 1999; 68(2): 542-548.

18. Shinoka T, Breuer CK, Tanel RE, et al. Tissue engineering heart valves: valve leaflet replacement study in a lamb model. Ann Thorac Surg 1995; 60(6 Suppl): S513-S516.

19. Colazzo F, Sarathchandra P, Smolenski RT, et al. Extracellular matrix production by adipose-derived stem cells: implications for heart valve tissue engineering. Biomaterials 2011; 32(1): 119-127.

20. Berry JL, Steen JA, Williams JK, et al. Bioreactors for development of tissue engineered heart valves. Ann Biomed Eng 2010; 38(11): 3272-3279.

21. Sauren A, Hout MC, Steenhaven AA, et al. The mechanical properties of porcine aortic valve tissues. $J$ Biomech 1983; 16: 327-337.

22. Sacks MS. Incorporation of experimentally-derived fiber orientation into a structural constitutive model for planar collagenous tissues. J Biomech Eng 2003; 125(2): 280-287.

23. Sacks MS and Sun W. Multiaxial mechanical behavior of biological materials. Annu Rev Biomed Eng 2003; 5: 251-284. 
24. Grashow JS, Sacks MS, Liao J, et al. Planar biaxial creep and stress relaxation of the mitral valve anterior leaflet. Ann Biomed Eng 2006; 34(10): 1509-1518.

25. Sacks MS. Biaxial mechanical evaluation of planar biological materials. $J$ Elast 2000; 61: 199-246.

26. Eilaghi A, Flanagan JG, Brodland GW, et al. Strain uniformity in biaxial specimens is highly sensitive to attachment details. J Biomech Eng 2009; 131(9): 091003.

27. Eilaghi A, Flanagan JG, Tertinegg I, et al. Biaxial mechanical testing of human sclera. J Biomech 2010; 43(9): 1696-1701.

28. Gregory DE, Veldhuis JH, Horst C, Brodland GW, Callaghan JP, Novel lap test determines the mechanics of delamination between annular lamellae of the intervertebral disc. Journal of Biomechanics 2011; 44:97-102.

29. Sun W, Sacks MS and Scott MJ. Effects of boundary conditions on the estimation of the planar biaxial mechanical properties of soft tissues. J Biomech Eng 2005; 127(4): 709-715.

30. Brown AN, Kim BS, Alsberg E, et al. Combining chondrocytes and smooth muscle cells to engineer hybrid soft tissue constructs. Tissue eng 2000; 6(4): 297-305.

31. Engelmayr GC Jr., Rabkin E, Sutherland FW, et al. The independent role of cyclic flexure in the early in vitro development of an engineered heart valve tissue. Biomaterials 2005; 26(2): 175-187.
32. Engelmayr GC Jr., Papworth GD, Watkins SC, et al. Guidance of engineered tissue collagen orientation by large-scale scaffold microstructures. J Biomech 2005; 39: 1819-1831.

33. Balguid A, Mol A, Van Vlimmeren MAA, et al. Hypoxia induces near-native mechanical properties in engineered heart valve tissue. Circulation 2009; 119(2): 290-297.

34. Christie GW and Barratt-Boyes BG. Mechanical properties of porcine pulmonary valve leaflets: how do they differ from aortic leaflets? Ann Thorac Surg 1995; 60(00034975): S195-S199.

35. Sacks MS, Smith DB and Hiester ED. The aortic valve microstructure: effects of transvalvular pressure. $J$ Biomed Mater Res 1998; 41(1): 131-141.

36. Billiar KL and Sacks MS. Biaxial mechanical properties of the natural and glutaraldehyde treated aortic valve cusp - part I: experimental results. J Biomech Eng 2000; 122(1): 23-30.

37. Stradins P, Lacis R, Ozolanta I, et al. Comparison of biomechanical and structural properties between human aortic and pulmonary valve. Eur J Cardiothorac Surg 2004; 26(3): 634-639.

38. Balguid A, Rubbens MP, Mol A, et al. The role of collagen cross-links in biomechanical behavior of human aortic heart valve leaflets - relevance for tissue engineering. Tissue Eng 2007; 13(7): 1501-1511. 